\title{
Multiple-load series resonant inverter for induction cooking application with pulse density modulation
}

\author{
P SHARATH KUMAR \\ Department of Electrical \& Electronics Engineering, CVR College of Engineering, Hyderabad, \\ Telangana 501510, India \\ e-mail: sharathphd@gmail.com
}

MS received 15 March 2016; accepted 28 September 2016

\begin{abstract}
Multiple-load induction cooking applications are suitable used when multi-output inverters or multi-inverters are needed for multiple-load operation. Some common approaches and modifications are needed in inverter configuration for multiple-load application. This paper presents an inverter configuration with two loads by using pulse density modulation control technique. It allows the output power control of each load independently with constant switching frequency and constant duty ratio. The pulse density modulation control technique is obtained using phase on-off control between two legs of the inverter to reduce acoustic noise. The two-load three-leg inverter configuration provides reduction of the component count for extension of multiple loads. The control technique provides a wide range of output power control. In addition, it can achieve efficient and stable zero voltage switching operation in the whole load range. The proposed control scheme is simulated and experimentally verified with two-load inverter configuration.
\end{abstract}

Keywords. Induction cooking; multiple load; series resonant inverter; ZVS; pulse density modulation control.

\section{Introduction}

Induction heating $(\mathrm{IH})$ method is a far better approach than conventional methods. In conventional methods, heat is transferred from a heat source to load by conduction or radiation. In IH, heat is developed inside the load due to generation of eddy currents at skin depth level from the surface [1]. In recent times, considerable progress has been made in control schemes and inverter configurations. Induction cooking is one of the several applications of IH. Figure 1 shows a typical arrangement of high-frequency IH circuit.

Resonant inverter is commonly used as a source of highfrequency AC supply. The DC input is derived by rectifying the utility AC source. High-frequency AC flowing in the load coil results in eddy currents induced in the vessel at skin depth level, resulting in a heating effect.

Commonly used topologies for induction cooking application are quasi resonant, half-bridge, and full-bridge inverter [2]. Out of these, full-bridge inverter is preferred for high-power applications.

In induction cooking application, variable frequency (VF) scheme, pulse frequency modulation (PFM), pulse amplitude modulation (PAM), phase shift modulation (PSM) and asymmetrical duty-cycle control technique are used for output power control [3-8]. In VF scheme to control the output power for a constant load by varying the normalised switching frequency above its resonant frequency, in case of below resonant frequency operation zero voltage switching (ZVS) is not possible and required filter components are large for the low-frequency range operation [3]. PFM control has a relatively narrow ZVS soft switching operating region. In PAM, control for constant load amplitude of the source voltage is varied to control the output power. PSM control shows high efficiency at higher duty ratio [4]. ADC control gives ZVS at higher duty ratios in full-bridge inverter configuration [5]. For reducing switching losses, it is mainly used in half-bridge topology. AVC control gives ZVS at lower duty ratios as well as in full-bridge inverter configuration. AVC control technique is mainly used in fullbridge topology [5-7]. In induction cooking application, one inverter feeds power to a single load. For multiple-load application, there is a need to develop inverter circuits and control techniques which can minimise component count and provide independent control of each load [8]. Certain techniques are available in the literature.

This paper proposes two-load three-leg series resonant inverter for induction cooking application with pulse density modulation control with phase on-off control technique. The three-leg inverter configuration powers two loads with independent output power control of each load. In this configuration, PDM control technique [9-14] is used with phase on-off control between two legs of an inverter for load output power control. The phase on-off control has no acoustic noise because the inverter switching frequency 


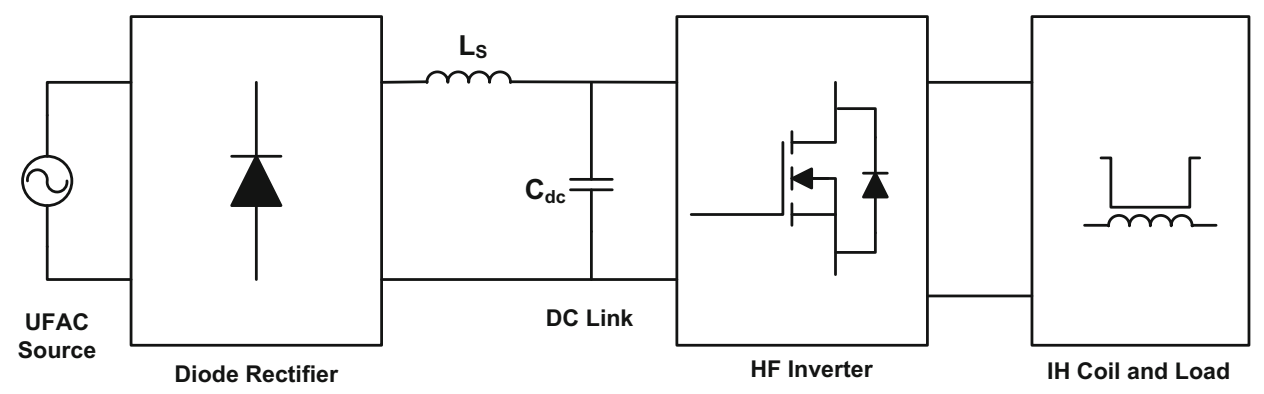

Figure 1. Typical arrangement of induction cooking resonant inverter.

is more than the audible range. But, in general, in PDM technique, the duration of the inverter gate pulse density should be less than the audible range. It can be overcome with phase on-off control technique. This configuration can be extended to multiple loads as well.

\section{Operating principle of IH and load characteristics}

\subsection{Operating principle of $I H$}

Operating principle of IH is that when IH coil is energised by high-frequency current, it produces magnetic flux. It causes eddy currents that occur in heating load and this result in heating effect. The induced eddy currents are concentrated at the vessel's bottom layer at skin depth $(\delta)$ level [2], which is explained by

$$
\delta=\sqrt{\frac{\rho}{\pi \mu f_{s}}}=\sqrt{\frac{1}{4 \pi^{2} \times 10^{-7}}} \times \sqrt{\frac{\rho}{\mu_{r} f_{s}}}
$$

where $\rho$ is the electrical resistivity, $\mu$ is the magnetic permeability and $\mu_{\mathrm{r}}$ is the relative magnetic permeability of load material and $f_{\mathrm{s}}$ is the switching frequency of the inverter circuit.

The load surface resistance $\left(R_{\mathrm{L}}\right)$ is determined by the load skin depth and its material specific resistance is shown in the following expression:

$$
R_{L}=\frac{\rho}{\delta}=k \sqrt{\rho \mu_{r} f_{s}}
$$

where $k$ is constant $=0.00198692$.
The load parameters depend on several variables, including the shape of the heating coil, the spacing between the heating coil and cooking vessel (load), load electrical conductivity and magnetic permeability, and the inverter switching frequency.

\subsection{Equivalent circuit of IH coil and load}

A linear equivalent model of the IH coil and load represented by the effective equivalent inductance $\left(L_{\mathrm{eq}}\right)$ in series with effective equivalent resistance $\left(R_{\text {eq }}\right)$ is referred to the input side of IH coil.

Figure 2 shows the equivalent circuits for $\mathrm{IH}$ coil with load parameters. Load parameters are taken as single-turn short-circuited secondary winding.

The circuit elements are represented as follows:

1. $R_{\mathrm{L}}$ surface resistance of the load

2. $L_{0}$ inductance of the load

3. $R_{1}$ resistance of IH coil

4. $L_{1}$ inductance of IH coil

5. $i_{0}, i_{1}$ load current and IH coil current

6. $M_{10}, M_{01}$ the mutual inductance between IH coil and load.

The voltage equations for the aforementioned equivalent circuit are as follows:

$$
\begin{aligned}
& v_{0}=i_{1} R_{1}+L_{1} \frac{d i_{1}}{d t}+M_{10} \frac{d i_{0}}{d t} \\
& 0=i_{0} R_{L}+L_{0} \frac{d i_{0}}{d t}+M_{01} \frac{d i_{1}}{d t}
\end{aligned}
$$

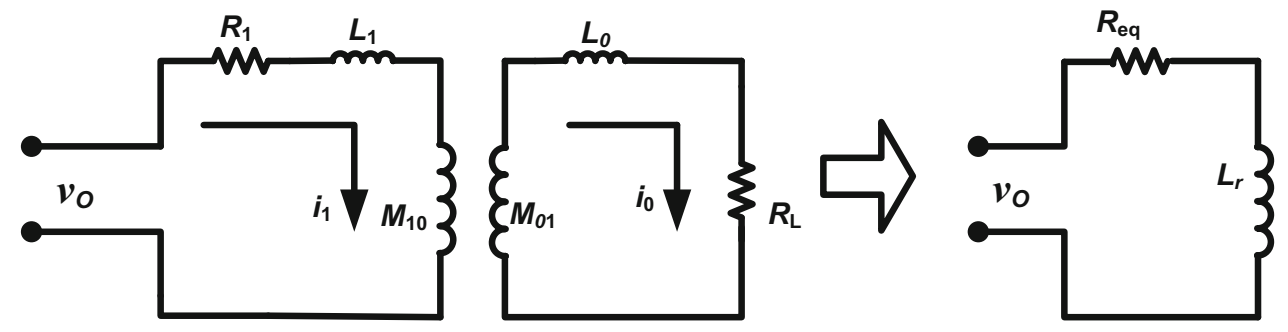

Figure 2. Equivalent circuit of IH coil with load. 
From (3) and (4) equations

$$
\begin{gathered}
R_{e q}=R_{1}+\frac{(\omega M)^{2} \cdot R_{\mathrm{L}}}{R_{\mathrm{L}}^{2}+\left(\omega L_{0}\right)^{2}} \\
L_{r}=\left\{L_{1}-\frac{(\omega M)^{2} \cdot L_{0}}{R_{\mathrm{L}}^{2}+\left(\omega L_{0}\right)^{2}}\right\} \\
R_{e q}=R_{1}+A^{2} R_{\mathrm{L}} \\
L_{r}=\left\{L_{1}-A^{2} L_{0}\right\}
\end{gathered}
$$

where $\quad M_{10}=M_{01}=M \quad$ and $\quad A=\frac{(\omega M)}{\sqrt{R_{L}^{2}+\left(\omega L_{0}\right)^{2}}}=\frac{M}{L_{0}} \quad$ at $\omega L_{0} \gg R_{L}$.

\section{Inverter configuration with proposed control scheme}

This section describes the two-load inverter configuration with proposed control scheme for two-load induction cooking application. Figure 3 shows the circuit diagram of two-load three-leg inverter configuration. The two loads are connected across the inverter output voltages $v_{\mathrm{AB}}$ and $v_{\mathrm{AC}}$, respectively.

The concept of series resonance is used with each load. The resonant load circuits are connected to leg-1, which is a common leg for both loads. They are marked as leg-1, leg-2 and leg-3, respectively. Load-1 consists of $C_{\mathrm{r} 1}, L_{\mathrm{r} 1}$ and $\mathrm{R}_{\mathrm{eq} 1}$, which are resonant capacitor, inductance of the load-1 and equivalent load resistance in series with resonant tank, respectively, which is connected between leg-1 and leg- 2 . Similarly for load-2, $C_{\mathrm{r} 2}, L_{\mathrm{r} 2}$ and $R_{\mathrm{eq} 2}$ are resonant capacitor, inductance of the load-2 and equivalent load resistance in series with resonant tank respectively, which is connected between leg-1 and leg-3.

\subsection{Characteristics of a resonant tank}

The resonant tank circuit of each load in a three-leg inverter circuit is shown in figure 3 . It can be described by the following parameters:

The resonant angular frequency is

$$
\omega_{r}=\frac{1}{\sqrt{L_{r} C_{r}}} .
$$

The normalised switching frequency is

$$
\omega_{n}=\frac{\omega_{s}}{\omega_{r}}
$$

where $\omega_{s}=$ switching angular frequency $=2 \pi \times f_{s}$ $f_{s}=$ switching frequency.

The characteristic impedance is

$$
Z_{0}=\sqrt{\frac{L_{r}}{C_{r}}}=\frac{1}{\omega_{r} C_{r}}=\omega_{r} L_{r} .
$$

The IH load quality factor is

$$
Q=\frac{\omega_{r} L_{r}}{R_{\mathrm{eq}}}=\frac{1}{\omega_{r} C_{r} R_{\mathrm{eq}}}=\frac{Z_{0}}{R_{\mathrm{eq}}} .
$$

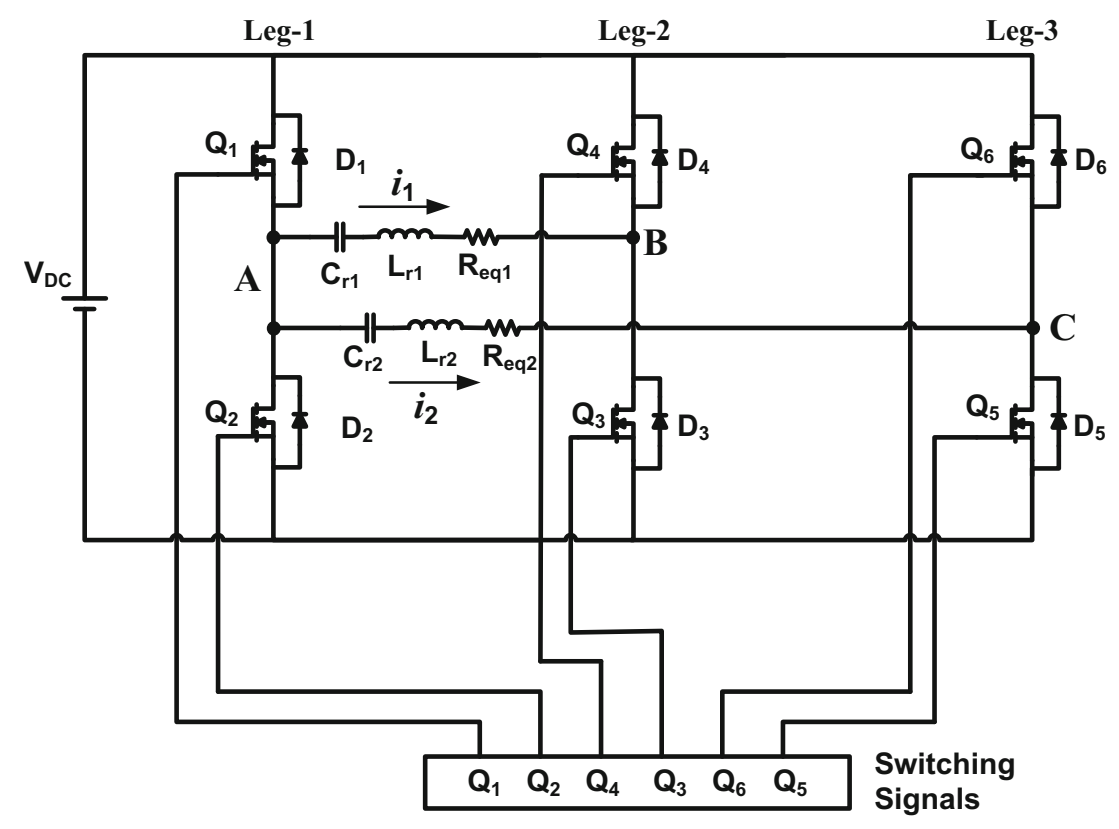

Figure 3. Two-load three-leg inverter configuration. 
The resonant tank circuit impedance is given by

$$
\begin{gathered}
Z_{\text {eq }}=R_{\text {eq }}+j\left(\omega_{s} L_{r}-\frac{1}{\omega_{s} C_{r}}\right) \\
=R_{\text {eq }}\left(1+j Q\left(\omega_{n}-\frac{1}{\omega_{n}}\right)\right) \\
\left|Z_{\text {eq }}\right|=R_{\text {eq }} \sqrt{1-Q^{2}\left(\omega_{n}-\frac{1}{\omega_{n}}\right)^{2}} .
\end{gathered}
$$

The phase-angle between output voltage and current is

$$
\emptyset=\tan ^{-1}\left(Q\left(\omega_{n}-\frac{1}{\omega_{n}}\right)\right) .
$$

\subsection{Pulse density modulation control technique}

Pulse density modulation control is obtained using phase on-off control technique. By making phase-in and phaseout sequence of switching pulses between two legs of fullbridge inverter circuit, we get phase on-off control technique. Figure 4 shows the switching pulses of an inverter circuit and inverter output voltage with its respective load current for a full-bridge circuit. $\mathrm{Q}_{3}$ switching pulses are phase-in and phase-out sequence with $\mathrm{Q}_{1}$ switching pulses. Similarly, $\mathrm{Q}_{4}$ switching pulses are with respect to $\mathrm{Q}_{2}$ switching pulses. When switching pulses are in phase-in sequence, inverter output voltage $V_{\mathrm{AB}}$ applied across load and switching pulses are in phase-out sequence, inverter output voltage $V_{\mathrm{AB}}$ becomes zero. The similar phase-in and phase-out sequences of switching pulses are applied for load-2 to obtain inverter output voltage $V_{\mathrm{AC}}$.

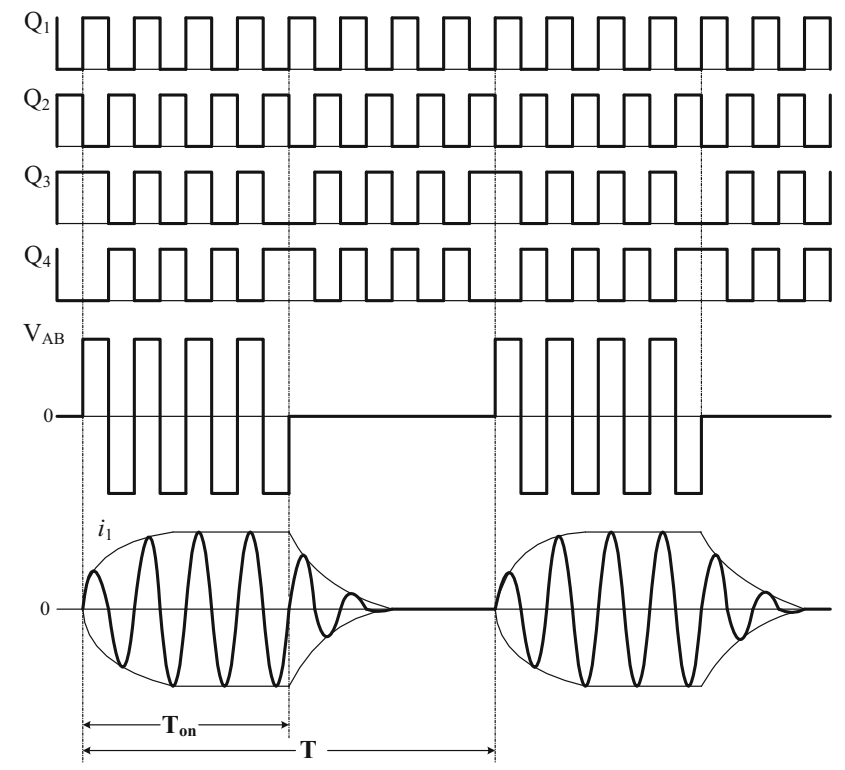

Figure 4. Inverter output voltage and load current with proposed PDM control technique of phase on-off control.
The time constant of the envelope of load current is given by

$$
\tau=\frac{2 L}{R_{\mathrm{eq}}}=\frac{2 Q}{\omega} .
$$

The envelope $i_{e}$ of resonant tank current is given by

$$
\begin{array}{r}
i_{e}(t)=I_{m}\left(1-e^{-\frac{t}{\tau}}\right)+I e^{-\frac{t}{\tau}} \quad \text { for } 0 \leq t \leq T_{\mathrm{on}} \\
i_{e}(t)=I\left(T_{\mathrm{on}}\right) e^{-\frac{\left(t-\mathrm{T}_{\mathrm{on}}\right)}{\tau}} \quad \text { for } T_{\mathrm{on}} \leq t \leq T
\end{array}
$$

where $I=I_{m} \frac{1-e^{-\frac{T_{0}}{\tau}}}{1-e^{-\frac{T}{\tau}}}$.

$I_{m}$ is the maximum current in full-power operation and $I$ is the initial value of the envelope $i_{\mathrm{e}}$.

Table 1. Parameters of two-load configuration.

\begin{tabular}{lcc}
\hline Item & Symbol & Value \\
\hline Source voltage & $V_{\mathrm{DC}}$ & $30 \mathrm{~V}$ \\
Equivalent resistance of each load & $R_{\mathrm{eq}}$ & $1.95 \Omega$ \\
$\begin{array}{l}\text { Equivalent inductance of each } \\
\quad \text { load }\end{array}$ & $L_{\mathrm{r}}$ & $68 \mu \mathrm{H}$ \\
Resonant capacitance of each & $C_{\mathrm{r}}$ & $0.45 \mu \mathrm{F}$ \\
$\quad$ load & & \\
Dead time in each leg & $t_{\mathrm{d}}$ & $450 \mathrm{~ns}$ \\
Time period for one PDM cycle & $T$ & $0.01 \mathrm{~s}$ \\
Resonant frequency of load & $f_{\mathrm{r}}$ & $28.77 \mathrm{kHz}$ \\
$\quad$ circuit & & \\
Switching frequency of each leg & $f_{\mathrm{s}}$ & $30 \mathrm{kHz}$ \\
$P_{\text {max }}$ & & $226 \mathrm{~W}$ \\
MOSFETs used & IRFP4110PbF & $100 \mathrm{~V}$, \\
& & $180 \mathrm{~A}$ \\
\hline
\end{tabular}

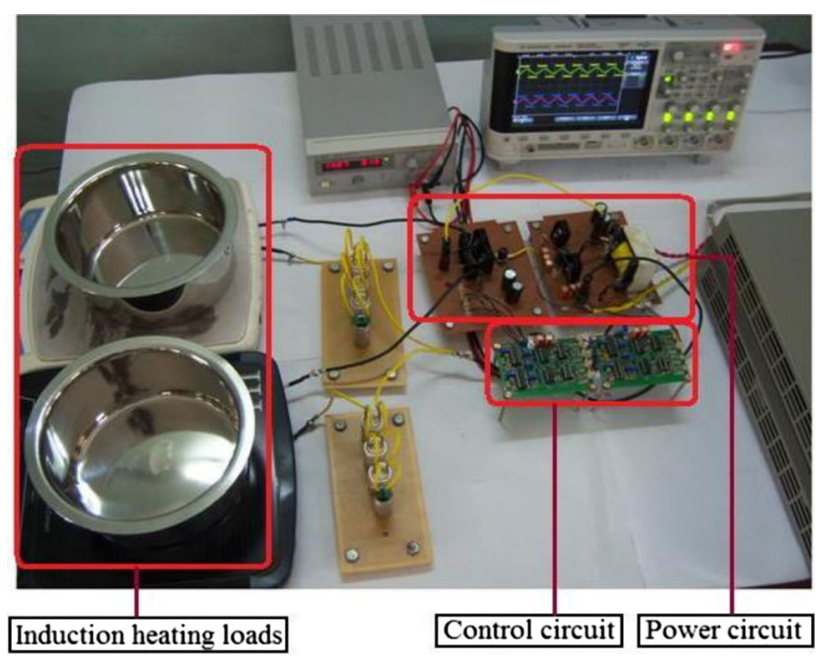

Figure 5. Experimental setup of a proposed inverter configuration. 
(a)
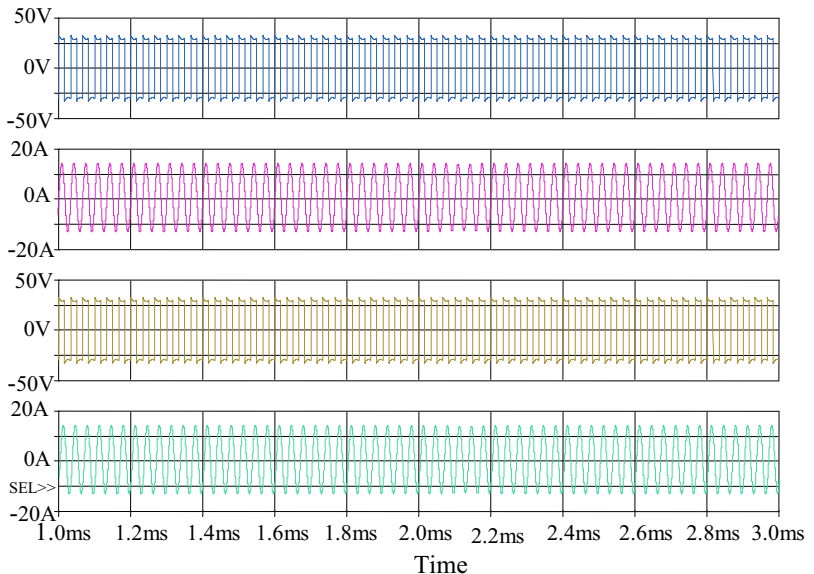

(b)

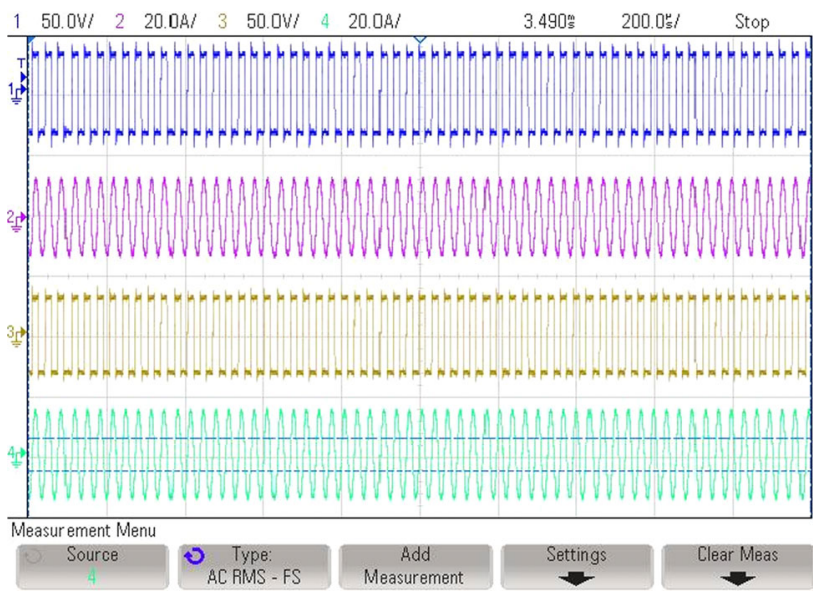

Figure 6. Two loads are operating at $100 \% D_{y}$.

The average power is obtained by multiplying $\mathrm{V}_{\mathrm{DC}}$ and $i_{\mathrm{e}}$, as follows:

$$
\begin{aligned}
P & =\frac{1}{T} \int_{0}^{T_{\mathrm{on}}} \frac{2}{\pi} V_{D C} i_{e}(t) d t \\
& =\frac{2}{\pi} V_{D C} I_{m} \frac{T_{\mathrm{on}}+\tau e^{-\frac{T_{\mathrm{on}}}{\tau}}-\tau}{T}+\frac{2}{\pi} V_{D C} I_{m} \frac{\tau e^{\frac{T_{\mathrm{on}}}{\tau}}-1}{T e^{\frac{T}{\tau}}-1}\left(1-e^{-\frac{T_{\mathrm{on}}}{\tau}}\right) .
\end{aligned}
$$

If the periodic time $T$ of the PDM control operation is much smaller than the time constant $\tau$, no fluctuation occurs in the amplitude of the resonant tank current and becomes a continuous waveform.

If the periodic time $T$ is much greater than the time constant $\tau$, the output power is in proportion to the pulse density because the resonant tank current becomes a discontinuous waveform. Thus, the input power is in proportion to the pulse density is given by

$$
\lim _{\tau \rightarrow 0} P=\frac{2}{\pi} V_{D C} I_{m} \frac{T_{\mathrm{on}}}{T}
$$

(a)

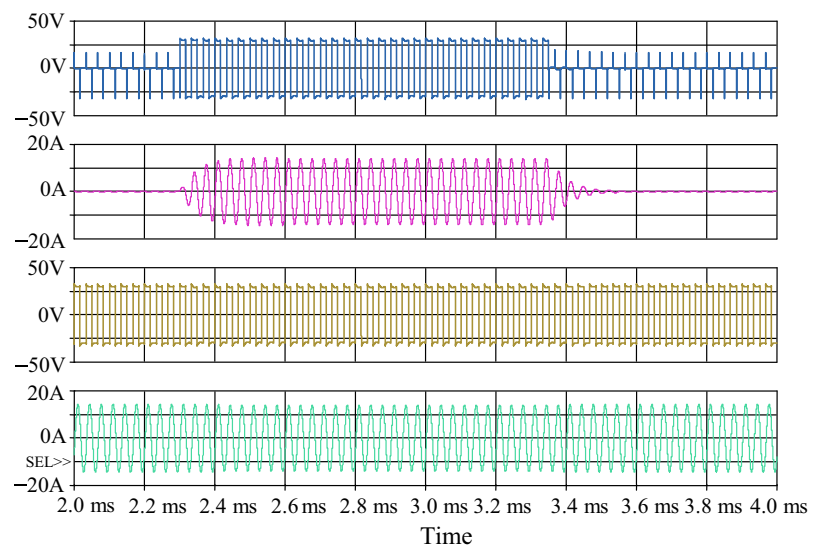

(b)

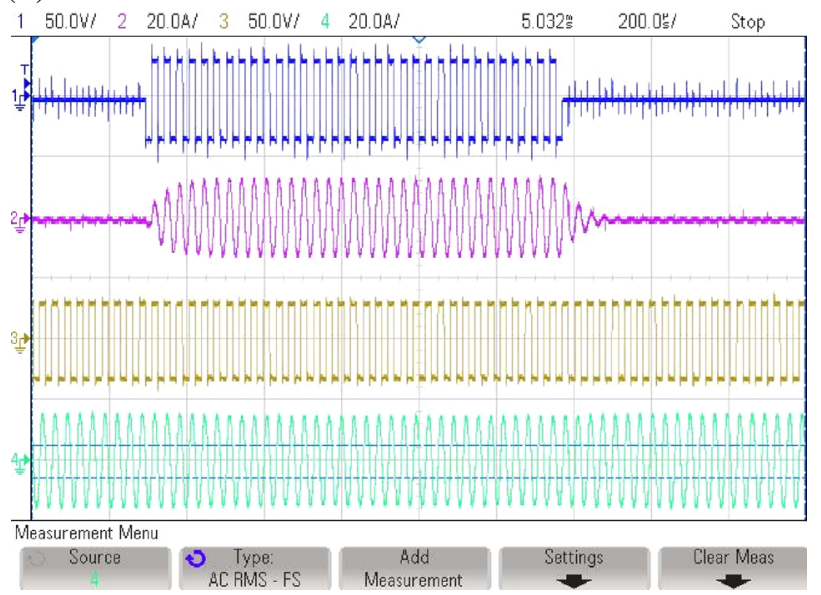

Figure 7. First load is operating at $11 \% D_{y}$.

Assuming, the inverter circuit losses are constant because of the inverter circuit operates with a constant switching frequency and constant duty-ratio. Thus, the output power is also in proportion to the pulse density is given by

$$
P_{\text {out }}=I^{2} R_{\text {eq }} \frac{T_{\text {on }}}{T}=P_{\text {max }} D_{y}
$$

where $I$ is the r.m.s. value of load current, $R_{\text {eq }}$ is the equivalent load resistance, $D_{y}$ is the pulse density ratio and $P_{\max }$ is the full output power under continuous condition.

In this paper, both loads have the same component values and their resonant frequencies are same. Hence, their power rating is also the same and operated at a switching frequency of $30 \mathrm{kHz}$. Resonant frequency of each load circuit is $f_{r}=\frac{1}{2 \pi \sqrt{L_{r} C_{r}}}$. Switching frequency of each leg is slightly higher than their resonant frequency. Hence, inverter switching frequency $\left(f_{s}\right)$ can be chosen $5-10 \%$ higher than the resonant frequency $\left(f_{r}\right)$ for ZVS operation. 
(a)

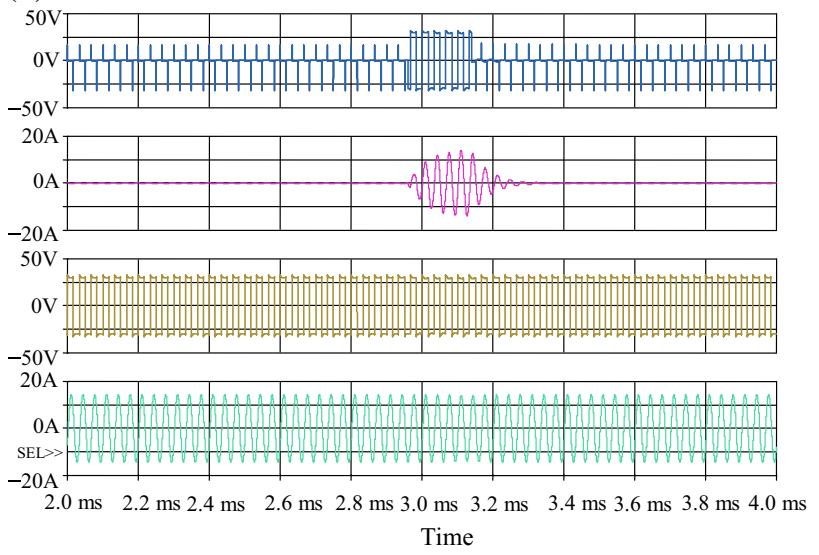

(b)

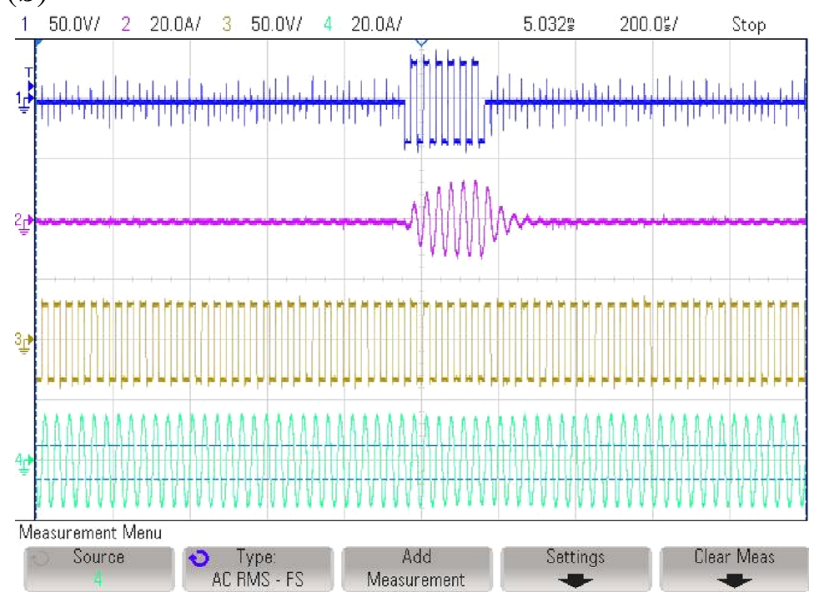

Figure 8. First load is operating at $2 \% D_{y}$.

\section{Results with proposed control technique}

The full-bridge series resonant inverter for two-load induction cooking application with three-leg is designed and operated at a constant switching frequency of $30 \mathrm{kHz}$. Two-load three-leg inverter configuration with PDM technique of phase on-off control is simulated and experimentally verified using the parameters shown in table 1 .

Experimental setup of two-load inverter configuration is shown in figure 5 .

\subsection{Simulation and experimental results}

The simulation and experimental results of two-load inverter configuration with PDM technique of phase on-off control are shown in figures $6,7,8,9$ for different $\% D_{y}$ combinations of load-1 and load-2.

Simulation waveforms of inverter output voltage and load currents are shown in figures 6(a), 7, 8, 9(a) at different $\% \mathrm{D}_{\mathrm{y}}$ combinations. These waveforms are shown under experimental condition in figures 6(b), 7, 8, 9(b). (a)
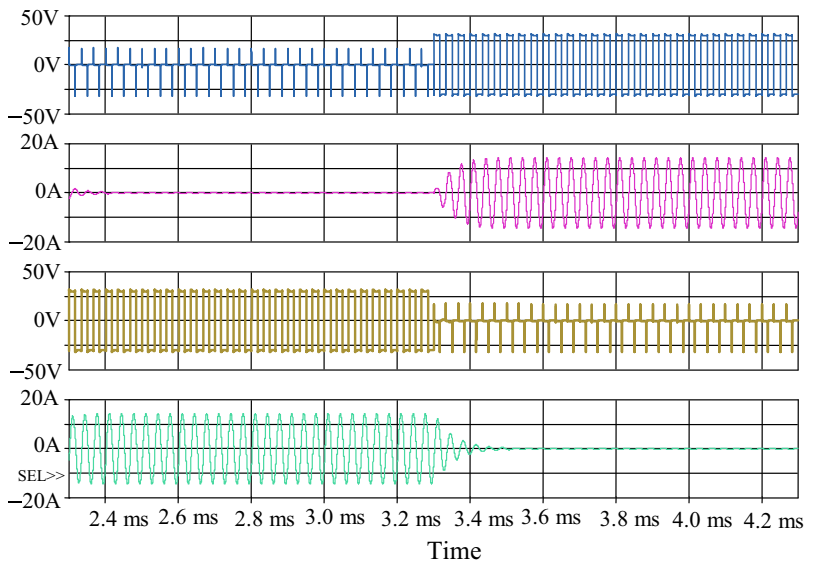

(b)

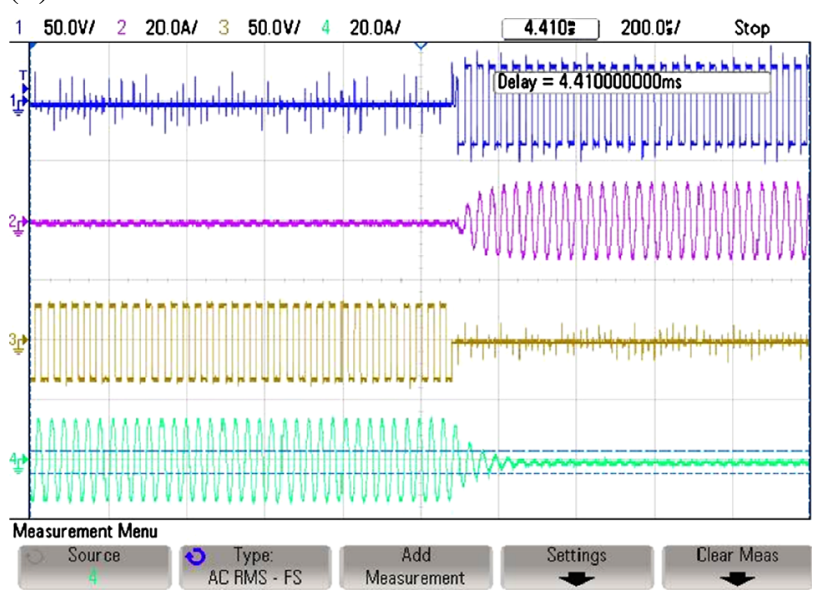

Figure 9. Both loads are operating at $50 \% D_{y}$.

Simulation and experimental waveforms are in good agreement.

\subsection{Control of output power}

In two-load configuration, both loads are similar and each load output power $\left(P_{\text {out }}\right)$ can be controlled independently with the phase on-off control technique. In the proposed phase on-off control technique, the time constant ' $\tau$ ' is $0.7 \%$ only of one PDM cycle periodic time $T$. So, the load current will be in discontinuous mode. The output power $\left(P_{\text {out }}\right)$ can be derived from Eqs. (21) and (22). The output power $\left(P_{\text {out }}\right)$ with percentage of pulse density $\left(\% \mathrm{D}_{\mathrm{y}}\right)$ is shown in table 2.

PDM is used with phase on-off control between two legs of inverter for load output power control. At zero inverter output voltage, the inverter operates in a freewheeling mode and the total stored energy in load will be discharged. PDM control technique offers smooth variation of power control from minimum to maximum value. From Eq. (22), the prototype $P_{\max }$ is $226 \mathrm{~W}$. The periodic time for one 
Table 2. Output power control with PDM control.

\begin{tabular}{lcc}
\hline S. no & $\% \mathrm{D}_{\mathrm{y}}$ & $P_{\text {out }}$ \\
\hline 1 & 100 & $225.76 \mathrm{~W}$ \\
2 & 80 & $180.61 \mathrm{~W}$ \\
3 & 60 & $135.45 \mathrm{~W}$ \\
4 & 50 & $112.88 \mathrm{~W}$ \\
5 & 40 & $90.3 \mathrm{~W}$ \\
6 & 30 & $67.73 \mathrm{~W}$ \\
7 & 20 & $45.15 \mathrm{~W}$ \\
8 & 2 & $4.515 \mathrm{~W}$ \\
\hline
\end{tabular}

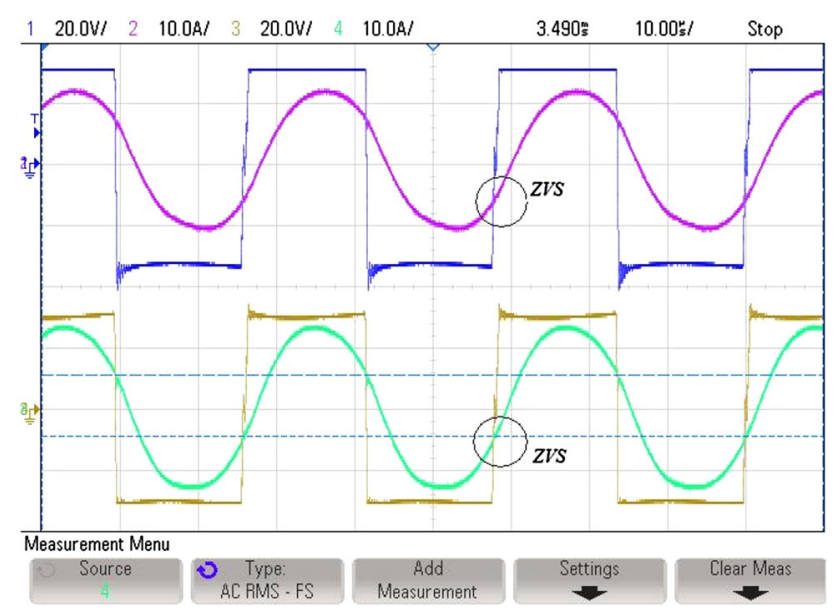

Figure 10. Both loads are operating with ZVS.

PDM cycle is taken as $0.01 \mathrm{~s}$, that is, $100 \mathrm{~Hz}$ is chosen and the switching pulses are generated without discontinuous mode to reduce acoustic noise.

\subsection{ZVS operation}

In a wide range of power control, the inverter operates with maximum and constant duty ratio with PDM control technique. For obtaining ZVS, the load current should be negative at turn-on of inverter output voltage.

Figure 10 shows that both loads operating with constant and maximum duty-ratio and load currents are in negative at inverter output voltage turn-on position. In a whole wide range, the inverter is operated with ZVS and also the inverter's overall efficiency is $96 \%$.

\section{Conclusion}

In this study, a two-load three-leg series resonant inverter configuration with PDM control technique for induction cooking application was proposed. PDM is used with phase on-off control between two legs of an inverter for load output power control. With the phase on-off control technique the acoustic noise is reduced in the audible range of PDM frequency as well. At zero inverter output voltage, the inverter operates in a freewheeling mode and the total stored energy in load is to be discharged. In this configuration, each load output power is controlled independently. The two-load inverter configuration is generalised into n-output series resonant inverter configuration with a saving of switching devices, that is, $2 n+2$ switching devices are required instant of $4 \mathrm{n}$ switching devices for a full-bridge configuration. In whole wide range of inverter operation, ZVS with constant and maximum duty ratio and constant switching frequency of $30 \mathrm{kHz}$ is ensured. Simulation and experimental results of the proposed configuration are in good agreement. Overall efficiency of this configuration is $96 \%$. The two-load inverter configuration can be extended to multiple loads.

\section{References}

[1] Moreland W C 1973 The induction range: its performance and its development problems. IEEE Trans. Ind. Appl. IA9(1): 81-85

[2] Mokhtar Kamli, Shigehiro Yamamoto and Minoru Abe 1996 A $50-150 \mathrm{kHz}$ half-bridge inverter for induction heating applications. IEEE Trans. Ind. Electron. 43(1): 163-172

[3] Young-Sup Kwon, Sang-Bong Yoo and Dong-Seok Hyun 1999 Half-bridge series resonant inverter for induction heating applications with load-adaptive PFM control strategy. In: 14th Applied Power Electronics Conference and Exposition, APEC' 99. 1: 575-581

[4] Grajales L, Sabate J A, Wang K R, Tabisz W A and Lee F C 1993 Design of a $10 \mathrm{~kW}, 500 \mathrm{kHz}$ phase-shift controlled series-resonant inverter for induction heating. Ind. Appl. Soc. Annu. Meet. 2: 843-849

[5] Bhaskar D V, Yagnyaseni N, Vishwanathan N and Maity T 2014 Comparison of control methods for high frequency IH cooking applications. In: Power and Energy Systems Conference: Towards Sustainable Energy. pp 1-6

[6] Burdio J M, Barragan L A, Monterde F, Navarro D and Acero J 2004 Asymmetrical voltage-cancellation control for full-bridge series resonant inverters. IEEE Trans. Power Electron. 19(2): 461-469

[7] Burdio J M, Monterde F, Garcia J R, Barragan L A and Martinez A 2005 A two-output series-resonant inverter for induction-heating cooking appliances. IEEE Trans. Power Electron. 20(4): 815-822

[8] Lucia O, Carretero C, Burdio J M, Acero J and Almazan F 2012 Multiple-output resonant matrix converter for multiple induction heaters. IEEE Trans. Ind. Appl. 48(4): 1387-1396

[9] Nam-Ju Park, Dong-Yun Lee and Dong-Seok Hyun 2007 A power-control scheme with constant switching frequency in class-D inverter for induction-heating jar application. IEEE Trans. Ind. Electron. 54(3): 1252-1260

[10] Jinfei Shen, Hongbin Ma,Wenxu Yan, Jing Hui and Lei Wu 2006 PDM and PSM hybrid power control of a series-resonant inverter for induction heating applications. IEEE Conf. Ind. Electron. Appl. ICIEA 
[11] Lucia O, Burdio J M, Millan I, Acero J and Puyal D 2009 Load-adaptive control algorithm of half-bridge series resonant inverter for domestic induction heating. IEEE Trans. Ind. Electron. 56(8): 3106-3116

[12] Fujita H, Akagi, Sano K, Mita K and Leonard R H 1993 Pulse density modulation based power control of a $4 \mathrm{~kW}$ $400 \mathrm{kHz}$ voltage-source inverter for induction heating applications. In: Power Conversion Conference, Yokohama, pp 111-116
[13] Lichan Meng, Ka Wai Eric Cheng and Ka Wing Chan 2011 Systematic approach to high-power and energy-efficient industrial induction cooker system: circuit design, control strategy, and prototype evaluation. IEEE Trans. Power Electron. 26(12): 3754-3765

[14] Sarnago H, Lucia O, Mediano A and Burdio J M 2013 Class D/DE dual-mode-operation resonant converter for improvedefficiency domestic induction heating system. IEEE Trans. Power Electron. 28(3): 1274-1285 